\title{
Estudio del esmalte dental humano por microscopía electrónica
}

\section{Study of the human tooth enamel by electron microscopy}

\author{
J. Reyes-Gasga (iDa,* \\ ${ }^{a}$ Instituto de Física, Universidad Nacional Autónoma de México. Circuito de la Investigación Científica s/n, Cd. Universitaria. Coyoacán 04510, México D. F., México
}

\begin{abstract}
Resumen
En el diente humano, la dentina y el esmalte presentan una estructura tipo compósito formada por cristales de hidroxiapatita (HAP) de tamaño nanométrico embebidos en una matriz de material orgánico. En este trabajo se describe el estudio de la estructura y composición química por microscopía electrónica del esmalte dental humano, así como del defecto llamado "línea obscura" (CDL) que se observa en el centro de los cristales del esmalte. Las imágenes del esmalte dental fueron tomadas por microscopia electrónica de transmisión (TEM) de alta resolución (HRTEM) y de microscopía electrónica de barrido transmisión (STEM) en el modo de detección anular de la dispersión a alto ángulo (STEM-HAADF). Los dientes humanos usados en este trabajo se obtuvieron de extracciones ortodóncicas. La preparación de las muestras se realizó por métodos metalográficos. Los resultados indican que la CDL se formó durante la amelogénesis y que es una zona con residuos de material orgánica.
\end{abstract}

Palabras Clave:

Diente humano, Esmalte dental humano, Línea oscura, Hidroxiapatita, Microscopia electrónica de transmisión.

\begin{abstract}
In human teeth, dentin and enamel have a composite structure formed by nano-sized hydroxyapatite crystals (HAP) embedded in a organic matrix. This work describes the study of the structure and chemical composition of human dental enamel by electron microscopy, as well as the defect observed in the center of the enamel crystals, named the "central dark line" (CDL). Images of tooth enamel were taken by high resolution transmission electron microscopy (TEM) (HRTEM) and transmission scanning electron microscopy (STEM) in high-angle scattering annular detection mode (STEM-HAADF). The human teeth used in this work were obtained from orthodontic extractions. The sample preparation was carried out by metallographic methods. The results indicate that CDL was formed during amelogenesis and it is a zone with residues of organic material.
\end{abstract}

Keywords:

Human tooth, Human tooth enamel, Central dark line, Hydroxyapatite, Transmission electron microscopy.

\section{Introducción}

El presente trabajo es la continuación del reporte de avances que sobre el esmalte dental humano he realizado por microscopía electrónica en el Instituto de Física de la UNAM (Reyes-Gasga et al., 2013).

El diente humano adulto tiene aproximadamente $2 \mathrm{~cm}$ de tamaño y está conformado por la dentina, que es el tejido conectivo que le otorga forma y rigidez. En la corona del diente, la dentina está cubierta por el esmalte, el tejido más resistente del cuerpo humano, y el cual se encarga de proteger a los dientes del desgaste que puede provocar la masticación.
Como es bien sabido, el esmalte dental humano es translúcido, su color depende de la dentina y varía entre blanco-amarillento y blanco-grisáceo. Ya que el esmalte difunde la luz blanca según su grado de mineralización, su transparencia se atribuye al grado de calcificación y homogeneidad que presenta. La figura 1 presenta las imágenes de microscopía electrónica de barrido (SEM, por sus siglas en inglés) de las estructuras prismáticas de tamaño micrométrico $\left(1\right.$ micra $\left.=10^{-6} \mathrm{~m}\right)$, que tienen forma de cerradura y que son compactados en un arreglo hexagonal de dimensiones micrométricas. La figura 1 también presenta la imagen de microscopía electrónica de transmisión (TEM, por sus siglas en inglés) de los cristales nanométricos $\left(1 \mathrm{~nm}=10^{-9} \mathrm{~m}\right)$ que conforman los prismas del esmalte dental humano (Reyes-

\footnotetext{
*Autor para la correspondencia: jreyes@fisica.unam.mx 
Gasga et al., 1995). Los prismas corresponden a las "líneas" que se observan en el esmalte entre la unión amelodentinaria y la superficie del diente en un diente cortado de tal manera que se observe tanto la dentina y el esmalte.

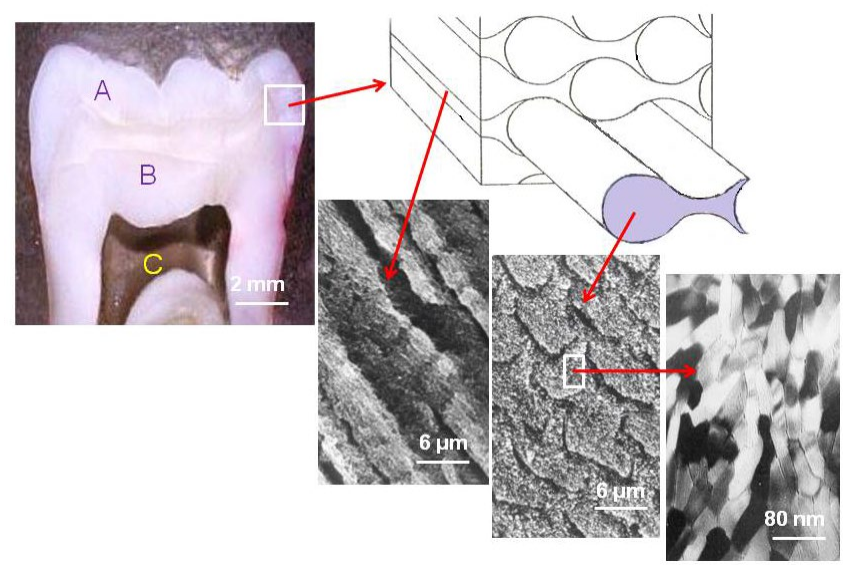

Figura 1. Elementos del diente humano. A) Esmalte, B) Dentina, C) Pulpa. El dibujo indica el arreglo hexagonal de los prismas en forma de "cerradura" del esmalte dental. Las imágenes de SEM presentan los prismas en direcciones longitudinal y transversal. La imagen de TEM presenta los cristales nanométricos de hidroxiapatita (Reyes-Gasga et al., 2013).

Los cristales nanométricos son cristales de hidroxiapatita (HAP, $\left.\mathrm{Ca}_{10}\left(\mathrm{PO}_{4}\right)_{6}(\mathrm{HO})_{2}\right)$ y están unidos lo más compacto posible, pero siempre rodeado de material orgánico. Por lo tanto, podemos clasificar al esmalte dental como un material tipo compósito. Recordemos que un material compósito es aquel en que dos o más materiales con diferentes propiedades mecánicas se unen para formar una estructura con propiedades mecánicas mejoradas.

El esmalte dental humano se compone de $96 \%$ de material inorgánico y $4 \%$ de material orgánico y agua. La parte inorgánica la conforma principalmente la HAP con impurezas de sodio, magnesio y cloro, entre otros elementos minoritarios. En la Figura 2 donde se presenta el espectro de los rayos $\mathrm{X}$ característico que se genera cuando hacemos incidir un haz de electrones sobre su superficie del esmalte (EDS, por sus siglas en inglés).

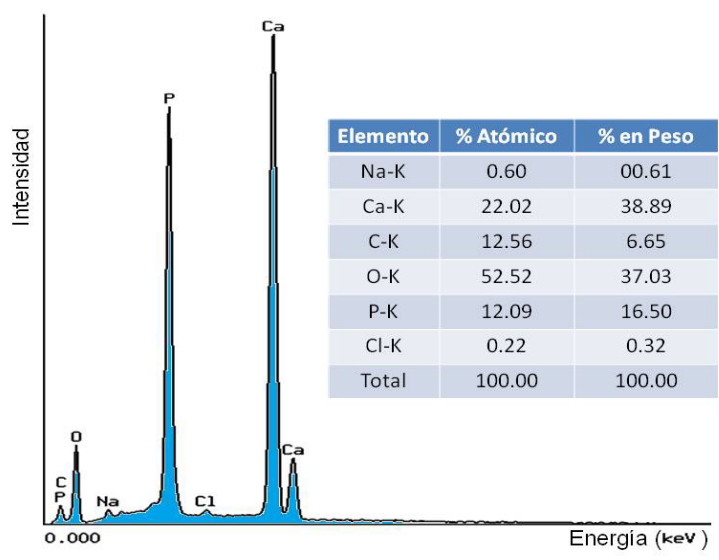

Figura 2. Análisis químico de EDS del esmalte dental humano. Se observan los elementos Calcio (Ca), Fosforo (P), Oxígeno (O), y Carbono, y en porcentajes minoritarios, Sodio (Na) y Cloro (Cl) (Reyes-Gasga et al., 2013).
Un dato importante en el estudio de la composición química del esmalte y la dentina es la relación que se obtiene entre el número de átomos de $\mathrm{Ca}$ con respecto al número de átomos de $\mathrm{P}$, lo que se conoce como la relación $\mathrm{Ca} / \mathrm{P}$. Esta relación se obtiene observando que la celda unitaria de la HAP contiene 10 átomos de Ca y 6 átomos de $\mathrm{P}$ (lo cual se complementa con 26 átomos de $\mathrm{O}$ y 2 átomos de $\mathrm{H}$ ). Entonces, el valor de la relación $\mathrm{Ca} / \mathrm{P}$ para la HAP sintética es de 1.67. Usando el valor del porcentaje atómico, en la figura 2 se obtiene 1.82, lo que indica una mayor concentración de $\mathrm{Ca}$ y/o una disminución de $\mathrm{P}$ en la muestra analizada. Los valores de la relación $\mathrm{Ca} / \mathrm{P}$ de muestras naturales como el esmalte y la dentina depende de varios factores, siendo la sustitución de los átomos de $\mathrm{Ca}$ y $\mathrm{P}$ por átomos de $\mathrm{Na}, \mathrm{Cl}$ y Mg su principal origen (LeGeros, 1991).

Para observar y estudiar los cristales nanométricos del prisma se usa un microscopio TEM; sólo se requiere que la muestra de esmalte tenga un espesor menor a los $10 \mathrm{~nm}$ aproximadamente (Reyes-Gasga et al., 1995). Un método sencillo para alcanzar estas dimensiones es hacer polvo el esmalte usando un esmeril (o la pieza de mano). El polvo se deposita sobre una rejilla de cobre de $3 \mathrm{~mm}$ de diámetro recubierta previamente con una película de plástico "colodión" y una película delgada de carbón. Otro método, el cual es más laborioso, implica el uso de técnicas metalográficas, como son los desgastes con papel lija, paños y el pulido a espejo con alúmina. El pulido final se obtiene erosionando atómicamente por medio de un haz iónico (conocido como pulidor "ion milling" por su nombre en inglés). Recientemente se inventó un equipo que consiste en "rebanar" la muestra usando un haz enfocado de iones de galio y permite obtener muestras con el espesor adecuado para su estudio por TEM; este equipo se llama FIB (por sus siglas en inglés). El tipo de estudio que se quiere realizar del esmalte dental, define el uso de un tipo de método de preparación u otro. Por ejemplo, el método de polvo se usa para hacer el estudio estructural y químico de cristales de manera individual, y el método metalográfico permite realizar el estudio de la interface entre los cristales y de las interacciones entre éstos. Junto con mis estudiantes, he usado todos estos métodos en el estudio del esmalte dental humano.

\section{Los cristales de HAP del esmalte dental humano}

La celda unitaria de la HAP es hexagonal con dimensiones a = $0.941 \mathrm{~nm}$ y c $=0.688 \mathrm{~nm}$, y con grupo espacial $\mathrm{P} 6_{3} / \mathrm{m}$. La figura 3 presenta esta celda unitaria en la dirección basal y en la dirección lateral. Toda la información cristalográfica de la celda unitaria de la HAP está registrada en la tarjeta de difracción de rayos X PDF No. 09-0432.

Aunque en forma natural la HAP también se presenta con una celda unitaria monoclínica, los estudios cristalográficos por microscopía electrónica de transmisión, al igual que los de difracción de rayos $\mathrm{X}$, demuestran que la celda unitaria de la HAP del esmalte dental es hexagonal (Reyes-Gasga et al., 2012). Esto también es confirmado por la difracción electrónica de los granos del esmalte dental humano (figura 4).

\section{Procedimiento experimental}

Se cortó el esmalte dental humano con un disco de diamante en rebanadas de $0.5 \mathrm{~mm}$ de espesor a partir de las cuales se obtuvieron muestras de $3 \times 3 \mathrm{~mm}$ con un grosor de 250 a 500 $\mu \mathrm{m}$. La reducción del espesor de la muestra y su aplanado se realiza por desbaste mecánico hasta espesores menores a 100 $\mu \mathrm{m}$. El último rebaje se realizó con la lija No. 1000 y el pulido 
espejo de las muestras con un paño microcloth y polvo de alúmina. Para limpiar la muestra, ésta se coloca en una mezcla de $60 \%$ isopropanol y $40 \%$ acetona, y se limpia ultrasónicamente durante 15 minutos. Para revelar su estructura y realizar su observación con un microscopio de luz y con el microscopio SEM, la muestra con terminación espejo se ataca con ácido fosfórico. Finalmente, la muestra se lava con agua destilada durante cinco minutos y se seca con aire comprimido.

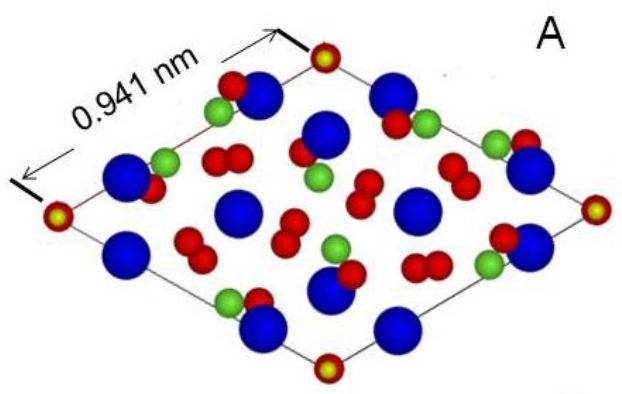

B

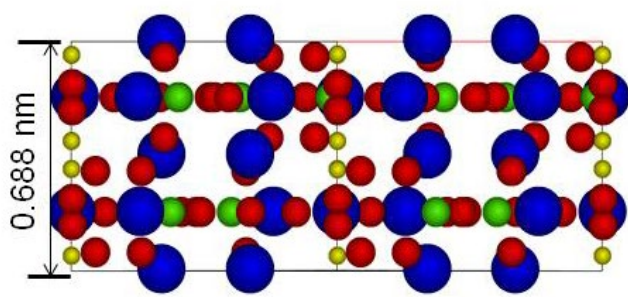

Figura 3. Representación de la celda unitaria hexagonal de la HAP mostrando el arreglo atómico de los átomos de Calcio (Ca, en color azul), Fosforo ( $P$, en color verde), Oxígeno (O, en color rojo) e Hidrógeno ( $H$, en color amarillo). A) Vista de su plano basal. B) Vista des su cara lateral(B).

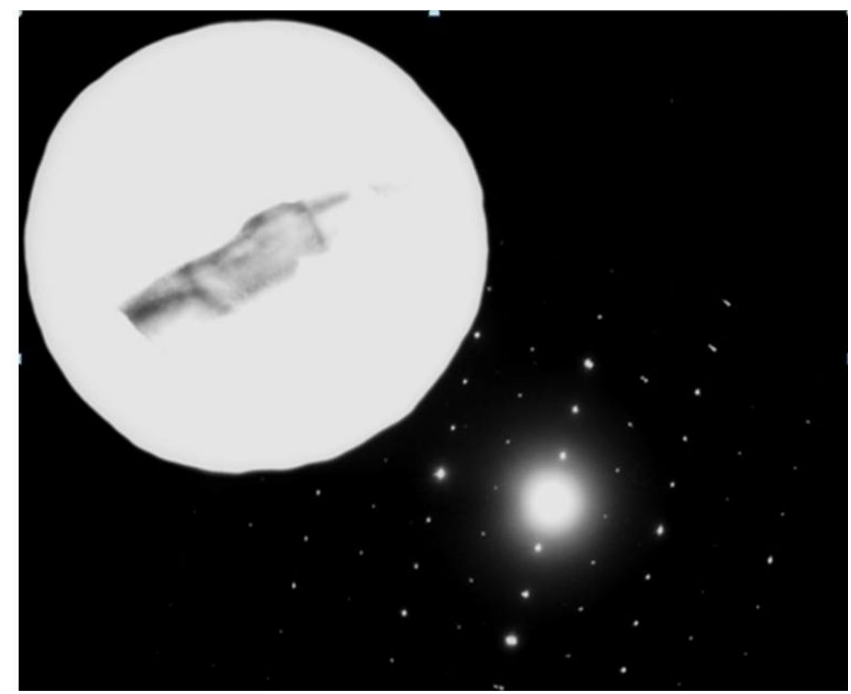

Figura 4. Patrón de difracción electrónica de un solo grano de esmalte dental humano (mostrado en el círculo). El análisis de los patrones de difracción indica que la celda unitaria del esmalte dental es hexagonal (Reyes-Gasga et al., 2013).
Para la observación de las muestras de esmalte por SEM se usó un microscopio SEM de emisión de campo FESEM JSM-7800F (Jeol, Tokio, Japan) con resolución de imagen de electrones secundarios de $1.0 \mathrm{~nm}$ para el voltaje de aceleración de $15 \mathrm{kV}$ y de $2.2 \mathrm{~nm}$ para el voltaje de aceleración de $1 \mathrm{kV}$. Para la observación de las muestras de esmalte por el TEM, se usó el equipo FIB de la marca FEI QUANTA modelo 200-3D (ThermoFisherScientific, Hillsboro, Oregón, EE. UU.) con iones de galio (Ga). El voltaje de aceleración fue de $30 \mathrm{kV}$ para el haz de electrones y para el haz de galio con corriente de emisión de $200 \mathrm{nA}$ para el haz de electrones y $50 \mathrm{nA}$ para el haz de iones. Para la colocación de la lámina de esmalte en una rejilla de cobre de TEM se usó el micromanipulador OmniprobeTM (Oxford Instruments, Abingdon, Reino Unido) 100.7, equipado con sistemas de inyección de gas para la deposición de platino $(\mathrm{Pt})$. Para la observación por TEM de alta resolución (HRTEM, por sus siglas en inglés) se usó un microscopio electrónico JEOL 2010-Fastem (Jeol, Tokio, Japón) equipado con filamento de emisión de campo operado a $200 \mathrm{kV}$, y cuya resolución es de $0.19 \mathrm{~nm}$. También se usó un microscopio Titan-300 FEI (ThermoFisherScientific, Hillsboro, Oregón, EE. UU.) equipado con un filamento de emisión de campo operado a $300 \mathrm{kV}$. Su resolución es de $0.20 \mathrm{~nm}$.

Las imágenes STEM se obtuvieron con el microscopio FEI QuAnt-EM en el EMAT de la Universidad de Amberes. Este es un microscopio FEI Titan G3 (FEI, Eindhoven, Países Bajos) equipado con un cañón de electrones de emisión de campo y correctores de aberraciones esféricas. Los correctores de doble aberración ofrecían una resolución espacial de $0.5 \AA$ en el modo TEM y de $0.8 \AA$ en el modo STEM y una elección flexible de voltajes de aceleración entre 60 y $300 \mathrm{kV}$. Se usó un portamuestras de doble inclinación en todas las observaciones por TEM y STEM.

\section{Imágenes a nivel nanométrico del esmalte dental}

La figura 5 presenta una imagen de HRTEM de un cristal nanométrico del esmalte dental. Las líneas corresponden a los planos interatómicos [10-10] de la celda unitaria de la HAP los cuales presentan una separación de $0.817 \mathrm{~nm}$. Debido a que el esmalte dental no es conductor eléctrico, al observar estos cristales por TEM se debe de tener en cuenta el hecho de al interaccionar con los electrones de haz incidente, los electrones quedan "atrapados" y cargan negativamente la superficie del esmalte. Esta interacción puede modificar la red cristalina del esmalte hasta provocarle cambios estructurales permanentes e irreversibles ya que, si electrones no son conducidos a "tierra", como sucede en el caso cuando se observan metales, los electrones "atrapados" en la muestra producen el daño conocido como "daño por radiación electrónica" y comienzan a destruirla (Reyes-Gasga et al., 1997, 1999, 2002, 2009). Este es el origen de los "parches" que se observan en la figura 5. Claramente, este daño electrónico representa una limitante en el tiempo de observación del esmalte dental humano por TEM. Una manera de de reducir este daño es recubriendo la muestra de esmalte con una capa delgada de carbón amorfo, la cual no elimina el daño, pero si alarga un poco más el tiempo de observación.

En la imagen de HRTEM del cristal del esmalte dental humano de la figura 5 se observa que el cristal presenta una línea de alto contraste en el centro (indicado por la flecha). El estudio de esta línea es muy importante ya que cuando el esmalte se somete a un proceso de disolución por medios ácidos, como en el caso del proceso carioso, los cristales del esmalte dental humano comienzan a disolverse a partir del centro del cristal (Brès et al., 
1983); es decir, exactamente en el lugar donde se encuentra este "defecto", al cual se le ha dado el nombre de "la línea obscura" (CDL).

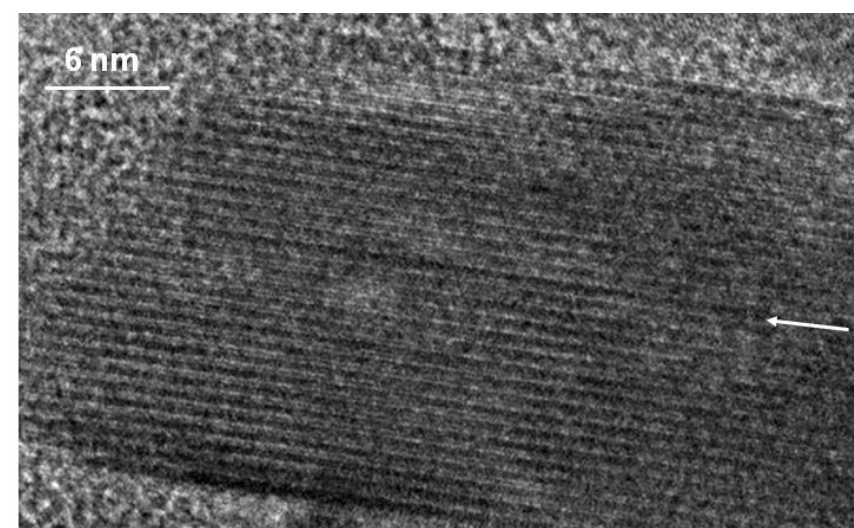

Figura 5. Imagen de HRTEM de uno de los cristales del esmalte dental humano mostrando la presencia de la línea obscura en centro (indicada por la flecha). Las líneas corresponden a los planos interatómicos $[10-10]$ de la celda unitaria de la HAP. También se observan pequeños "parches" producido por el daño electrónico.

\section{La línea obscura CDL}

Para entender la estructura y la composición química del esmalte dental humano, así como su cristalografía es necesario caracterizar y entender completamente el papel que juega la CDL en la estructura del esmalte (Reyes-Gasga and Brès, 2015). A pesar de los equipos modernos de TEM y HRTEM, el estudio estructural y químico de la CDL son temas nada fáciles de llevar a cabo. Hay que tomar en cuenta que la CDL representa un defecto que tiene un espesor de alrededor de $1 \mathrm{~nm}$, y que su contraste es fuertemente dependiente del foco del microscopio: cuando la imagen del cristal del esmalte esta sobre-enfocado la línea aparece obscura (de ahí su nombre), cuando está desenfocada aparece blanca, y desaparece en foco exacto (ReyesGasga et al., 1995).

La CDL no es un defecto lineal sino planar. En el cristal del esmalte, la CDL se encuentra localizada en el plano formado por las direcciones [11-20] y [0001]. Recientemente se ha reportado un cambio de concentración en la región de la CDL ya que se presenta un mayor porcentaje de $\mathrm{Mg}^{2+}$ y de $\mathrm{Na}^{+}$en el centro del cristal del esmalte. El ancho FWHM del perfil de concentración de $\mathrm{Mg}$ a través del CDL es de alrededor de $1 \mathrm{~nm}$, lo cual concuerda con el ancho de la CDL (DeRocher et al., 2020; Yun et al., 2020).

Existen varias hipótesis sobre la estructura y composición química de la CDL y sobre el papel que juega en la estructura del esmalte dental humano. Se ha comentado que ésta puede ser producto de una descalcificación, un conjunto de dislocaciones, una frontera de grano, etc. También se sugirió la idea que la línea obscura es el residuo de un material diferente a la HAP que se originó durante la amelogénesis (de aquí que se disuelva primero durante un ataque ácido, Bres et al., (1983)). Así, la CDL se presenta como resultado de la existencia de otro material que se produjo antes que el cristal de hidroxiapatita y que funcionó como base para que el cristal de HAP nucleara y creciera y diera origen al esmalte. Se propuso que este material es otro fosfato cálcico, llamado fosfato octacálcico (Fernández et al., 2003; Arellano-Jiménez et al., 2009). Sin embargo, hasta el momento, ninguna de estas ideas ha sido completamente comprobada.

\section{Observación de los átomos del esmalte dental humano}

Los átomos del esmalte dental humano se han "observado" por TEM, tanto en el modo de alta resolución (HRTEM) y en el modo de barrido transmisión (STEM) en contraste $Z$ de alta resolución (STEM-HAADF). Sin embargo, los contrastes observados son diferentes y requieren información adicional. Como es bien sabido, las imágenes de HRTEM son en realidad patrones de interferencia (Williams and Carter, 2009). Por lo tanto, para la interpretación de las imágenes de HRTEM se requiere el contar con la simulación computacional del contraste. La figura 6 presenta las imágenes de HRTEM en las direcciones [0001] (figura 6A) y [21-10] (figura 6B). Las imágenes sobrepuestas en la figura 6 presentan las imágenes simuladas de HRTEM de la celda de la HAP, e indican las posiciones de los átomos de calcio $(\mathrm{Ca})$, fósforo $(\mathrm{P})$, oxígeno $(\mathrm{O})$, e hidrógeno $(\mathrm{H})$. El contraste tanto de las imágenes simuladas y de las imágenes experimentales son muy similares y las posiciones de los átomos son obtenidas. A pesar de esto, es necesario tener presente que las posiciones precisas de los átomos dependen de los valores del espesor de la muestra y del desenfoque entre otros parámetros. Esto resulta en la "deslocalización" de las posiciones de los átomos.

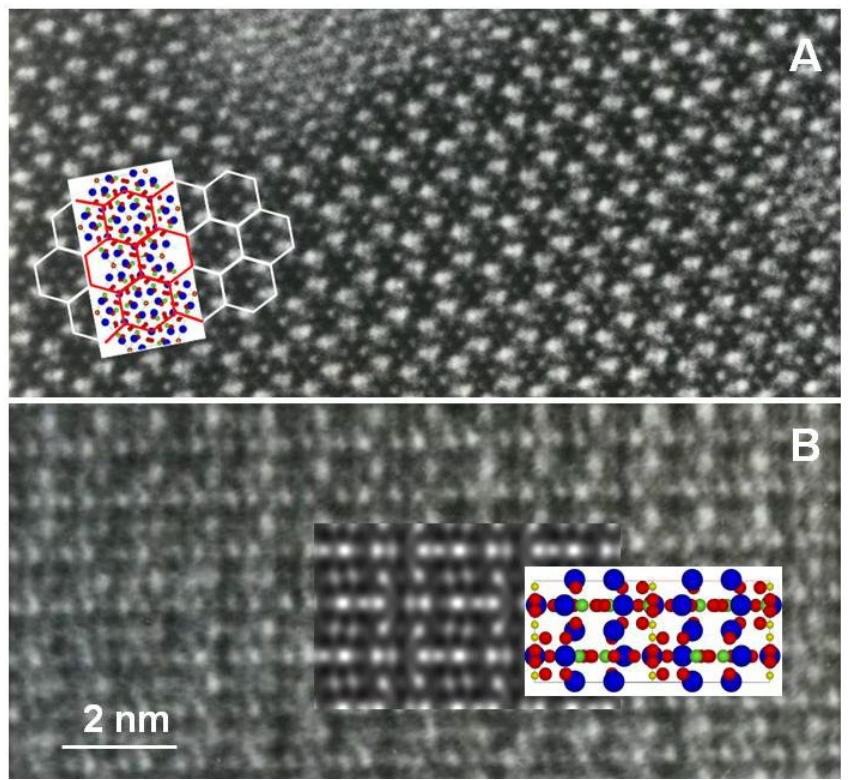

Figura 6. Imágenes de HRTEM del esmalte dental humano en las direcciones [0001] (A) y [21-10] (B). Las imágenes sobrepuestas presentan la celda de la HAP y las correspondientes posiciones de los átomos. Calcio (Ca) en azul, fósforo $(\mathrm{P})$ en verde, oxígeno $(\mathrm{O})$ en rojo, e hidrógeno (H) en amarillo (Reyes-Gasga et al., 2015).

Por otro lado, es interesante el contraste que presenta la CDL cuando se observa con el microscopio STEM (Reyes-Gasga et al., 2008). La fuente de información para las imágenes de STEM son los electrones del haz electrónico dispersados a diferentes ángulos. En el caso de las imágenes de HRTEM, los electrones usados para formar su contraste son aquellos dispersados en ángulos muy pequeños; los electrones que conforman el patrón de difracción electrónico, la dispersión de Bragg, son menores a $1.0^{\circ}$. Los microscopios electrónicos modernos STEM están equipados con sistemas de corrección de aberraciones, y con el uso de detectores de electrones anulares dispersados en ángulos pequeños (entre 1.15 y $2.85^{\circ}$ ) y grandes (entre 2.86 y $14.5^{\circ}$ ). Usando los electrones que no son dispersados (los electrones transmitidos) se obtienen las imágenes de campo claro (BF), las 
cuales son similares a las imágenes de HRTEM.; cuando se usan los electrones dispersados en ángulo pequeño, se obtienen las imágenes de campo oscuro anular de bajo ángulo (ADF) y cuando se usan los electrones dispersados en ángulo grade se obtienen las imágenes de campo oscuro de alto ángulo (HAADF o contraste Z). Actualmente, cuando se usa un microscopio STEM con aberración corregida, todas estas imágenes se obtienen con resolución sub-angstrom (Haider et al., 1998). La Figura 7 presenta la imagen de STEM-HAADF (contraste-Z) del esmalte dental humano con resolución atómica. En este caso el contraste se interpreta en función del número atómico, siendo el de mayor intensidad el que corresponde al número atómico mayor (Reyes-Gasga et al., 2016). El número atómico $\mathrm{Z}$ del $\mathrm{Ca}$ es 20 , el de $\mathrm{P}$ es 15 , el de $\mathrm{O}$ es 8 , y el de $\mathrm{H}$ es 1 . Por lo tanto, los puntos brillantes estarán relacionados con los átomos de $\mathrm{Ca}$, seguidos en intensidad por los átomos de $\mathrm{P}$. Los átomos de $\mathrm{O} \mathrm{y}$ de $\mathrm{H}$ presentarán una intensidad mínima. De esta manera el contraste de estas imágenes se interpreta de forma directa.

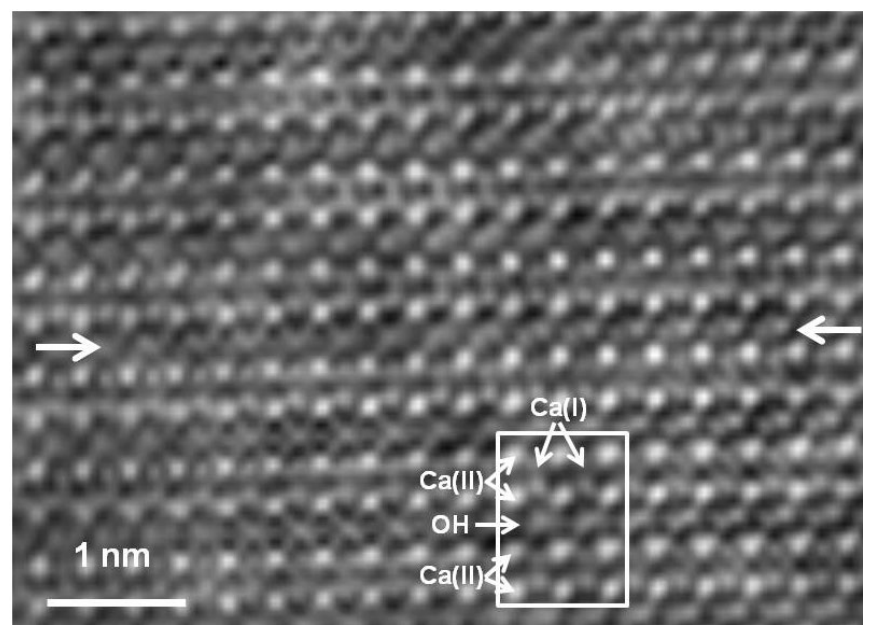

Figura 7. Imagen de STEM-HAADF (contraste-Z) del esmalte dental humano. El contraste se interpreta en función del número atómico, siendo el de mayor intensidad el calcio. Las flechas indican la posición de la CDL (Reyes-Gasga et al., 2016).

\section{Conclusiones}

Las imágenes de HAADF-STEM indican que el espesor de la CDL se encuentra entre 0.4 y $0.8 \mathrm{~nm}$. Debido a la diferencia en concentración química que presenta la CDL, el plano [1-210] de la celda unitaria hexagonal de HAP sobre el cual pasa la CDL divide al cristal del esmalte en dos partes las cuales se relacionan por un plano espejo $m$. Este resultado también implica una reducción de simetría de la celda de HAP sobre la que se encuentra la CDL. La diferencia en concentración química indica que la sobreposición de los átomos de la celda de HAP produce la existencia de esfuerzos y deformaciones. Se supone que esta zona de deformaciones es rica en $\mathrm{Mg}$ y en $\mathrm{Na}$ (DeRocher et al., 2020; Yun et al., 2020), lo cual explica bien con la disolución preferencial en medios ácidos del cristal del esmalte.

Para la interpretación de la estructura de la CDL, se ha sugerido que ésta tiene su origen durante la amelogénesis, cuando el cristal del esmalte dental comienza a crecer desde este sitio central, y la cual adsorbe iones de impurezas de todo el cristal para que se concentren ahí (DeRocher et al., 2020; Yun et al., 2020). Así, la segregación de iones de impurezas como $\mathrm{Mg}^{2+} \mathrm{y}$ $\mathrm{Na}^{+}$hace a la CDL propensa a perder su contenido mineral bajo un ataque de ácido externo.
Los resultados de TEM y STEM sobre la CDL son muy prometedores, pero aún faltan varias pruebas que se debe pasar antes de llegar a conclusiones definitivas. Y en eso estamos trabajando. Todo resultado adicional en esta dirección será importante para establecer o anular la validez de este modelo.

\section{Agradecimientos}

Agradezco al Dr. Ramiro García García, al Prof. Dr. Etienne F. Brès, y a mis estudiantes de licenciatura, maestría y doctorado por haber colaborado conmigo en la preparación de varios trabajos escritos sobre este tema. También agradezco a los Profores Dr. Gustaaf Van Tendeloo, Dr. Johan Verbeeck, y Dr. Stuart Torner del EMAT de la Universidad de Antwerpen (Bélgica) por el apoyo que me brindaron a través del proyecto ESTEEM y el Séptimo Programa en el Marco de la Unión Europea en virtud del Acuerdo de Subvención 312483ESTEEM2 (Iniciativa de Infraestructura Integrada-I3). Agradezco también a Samuel Tehuacanero Núñez y Pablo López por el apoyo técnico en el estudio del esmalte dental humano e hidroxiapatita. Este trabajo fue apoyado económicamente por la DGAPAUNAM con el proyecto PAPIIT-IN101319.

\section{Referencias}

Arellano-Jiménez, M. J., Garcia-Garcia R., Reyes-Gasga, J., (2009). Synthesis and hydrolysis of octacalcium phosphate and its characterization by electron microscopy and x-ray diffraction. J. Physics Chemistry Solids 70, 390-395.

DOI:10.1016/j.jcps.2008.11.001

Brès, E.F., Barry, J.C., Hutchison, J.L., (1983). A structural basis for the carious dissolution of the apatite crystals of human tooth enamel. Ultramicroscopy 12, 367-372. DOI:10.1016/0304-3991(83)90250-4.

DeRocher, K. A., Smeets, P. J. M., Goodge, B. H., Zachman, M. J., Balachandran, P. V., Stegbauer, L., Cohen, M. J., Gordon, L. M., Rondinelli, J. M., Kourkoutis, L. F., Joester, D., (2020). Chemical gradients in human enamel crystallites. Nature 583, 66 DOI: $10.1038 / \mathrm{s} 41586-020-2433-3$

Fernández, M. E., Zorrilla-Cangas, C., García-García, R., Ascencio, J. A., Reyes-Gasga, J., (2003). New model for the hydroxyapatite-octocalcium phosphate interface. Acta Crystallographica B59, 175-181. DOI:10-1107/S0108768103002167.

Haider, M., Rose, H., Uhlemann, S., Schwan, E., Kabius, B., Urban, K., (1998). A spherical-aberration-corrected $200 \mathrm{kV}$ transmission electron microscope. Ultramicroscopy 75, 53-60. DOI: $10.1016 / \mathrm{S} 0304-3991(98) 00048-5$.

LeGeros, R. Z., (1991). Calcium Phosphates in Oral Biology and Medicine. Basel: S. Karger, AG. ISBN: 978-3-8055-5236-3. DOI: 10.1159/isbn.978-3-318-04021-0.

Reyes-Gasga, J., (2013). Observación del esmalte dental humano con microscopía electrónica. Revista Tamé de la Universidad Autónoma de Nayarit. 1, 90-96. ISSN: 2007-462X

Reyes-Gasga, J., Carbajal-de-la-Torre, G., Bres, E., Gil-Chavarria, I. M., Rodriguez-Hernandez, A. G., Garcia-Garcia, R., (2008). STEM-HAADF electron microscopy analysis of the central dark line defect of human tooth enamel crystallites. J Mater Sci: Mater Med. 19, 877-882. DOI: $10.1007 / \mathrm{s} 10856-007-3174-7$.

Reyes-Gasga, J., Bres, E. F., (2015). Electron microscopic study of the human tooth enamel: the central dark line. Encyclopedia of Analytical Chemistry a9495. DOI: $10.1002 / 9780470027318$.

Reyes-Gasga, J., García, R., Alvárez-Fregoso, O., Chávez-Carvayar, J., Vargas-Ulloa, L., (1999). Conductivity in human tooth enamel. J. Materials Science 34, 2183-2188. DOI: $10.1023 / \mathrm{A}: 10045406170013$

Reyes-Gasga, J., García, R., Vargas-Ulloa, L., (1997). In-situ observation of fractal structures and electrical conductivity in human tooth enamel. Philosophical Magazine A 75, 1023-1040. DOI: $10.1080 / 01418619708214008$. 
Reyes-Gasga, J., García-García, R., (2002). Analysis of the electron-beam radiation damage of TEM samples in the acceleration energy in the range from 0.1 to $2 \mathrm{MeV}$ using the standard theory for fast electrons. Radiation Physics and Chemistry 64, 359-367. DOI: 10.1016/S0969-806X(01)00578-3.

Reyes-Gasga, J., Garcia-Garcia, R., Bres, E., (2009). Electron beam interaction, damage and reconstruction of hydroxyapatite. Physica B 404, 1867-1873.

DOI: $10.1016 / \mathrm{j}$-physb.2009.03.008.

Reyes-Gasga, J., Gloria, M. J., González, A. M., Madrigal, A., (1995). La microscopía electrónica y el esmalte dental humano. Revista Ciencia y Desarrollo CONACYT. México. Volumen XXI, No. 125, Noviembre/ Diciembre, pp. 30

Reyes-Gasga, J., Hémmerlé, J., Brès, E. F., (2016). Aberration-corrected transmission electron microscopic study of the central dark line defect in human tooth enamel crystals. Microscopy and Microanalysis 22, 1047 1055 .

DOI: $10.1017 / \mathrm{S} 1431927616011648$

Reyes-Gasga, J., Martínez-Piñeiro, E. L., Bres, E. F. (2012). Crystallographic structure of human tooth enamel by electron microscopy and x-ray diffraction: hexagonal or monoclinic?. J. Microscopy 248, 102-109. DOI: 10.1111/j.1365-2818.2012.03653.x.

Williams, D.B., Carter, C.B., (2009). Transmission electron microscopy, A texbook for material science. Springer-Verlag, M.A. Print ISBN: 978-0387-76500-6, pags. 173-193.

Yun, F., Swain, M. V., Chen, H., Cairney, J., Qu, J., Sha, G., Liu, H., Ringer, S. P., Han, Y., Liu, L., Zhang, X., Zheng, R., (2020). Nanoscale pathways for human tooth decay - Central planar defect, organic rich precipitate and high-angle grain boundary. Biomaterials 235, 119748. DOI:10.1016/j.biomaterials.2019.119748. 